\title{
SUBJETIVIDADE E TERRITÓRIO EM EMPREENDEDORES DE PRIMEIRA GERAÇÃO
}

\author{
SUBJECTIVITY AND TERRITORY IN FIRST ENTREPRENEURS GENERATION \\ SUBJETIVIDAD Y TERRITORIO EN EMPRENDEDORES DE PRIMERA GENERACIÓN
}

Andrea Pujol

\begin{abstract}
RESUMO
O empreendedorismo como ocupação é abordado em uma perspectiva cultural e a relação estabelecida com o território é analisada. $\mathrm{O}$ artigo reflete sobre o papel do território, na modelagem de projetos profissionais, o seu impacto sobre o futuro do empreendedorismo e como ele interage com o território, em seu contexto próprio. Do ponto de vista metodológico, a pesquisa é parte da tradição compreensiva e baseia-se em entrevistas biográficas, a fim de reconstruir e analisar as trajetórias dos empresários de uma amostra intencional de empresários da Argentina e do Uruguai. Os resultados referem-se principalmente às maneiras pelas quais projetos ocupacionais são acoplados a estilos de vida, a crises e à necessidade de resolvêlos, na estruturação da atividade. Por sua vez, discute-se, dialeticamente, a forma como o território imrime sua marca nesses projetos.
\end{abstract}

Palavras-chave: Empresários. Subjetividade. Território.

\begin{abstract}
In this article, entrepreneurship as occupation is approached from a cultural perspective and entrepreneurial relationship established with the territory is analyzed. It reflects on the role of territory in modeling of occupational projects, their impact on the future of entrepreneurship and how it interacts with the territory in the context. From the methodological point of view, research is part of the hermeneutics tradition and relies on biographical interviews in order to reconstruct and analyze the trajectories of entrepreneurs from a purposive sample of entrepreneurs from Argentina and Uruguay. The findings mainly relate to the ways in which occupational projects are coupled with lifestyles, crises and the need to address them in structuring of activity and in dialectical relationship, the way the territory its mark on projects.
\end{abstract}

Keywords: Entrepreneurs. Subjectivity. Territory.

* Docente y investigadora de la Facultad de Psicología de la Universidad Nacional de Córdoba. E-mail: apujol@psyche.unc.edu.ar 


\section{RESUMEN}

Se aborda la actividad emprendedora como ocupación desde una perspectiva cultural y se analiza la relación que el emprendedor establece con el territorio. Se reflexiona sobre el papel del territorio en el modelaje de los proyectos ocupacionales, su incidencia en el devenir del emprendimiento y el modo en que interactúa con el territorio en el contexto. Desde el punto de vista metodológico, la investigación se inscribe en la tradición comprensiva y se apoya en entrevistas biográficas, con el fin de reconstruir y analizar las trayectorias de emprendedores de una muestra intencional de empresarios de Argentina y Uruguay. Los hallazgos refieren principalmente a los modos en que se acoplan proyectos ocupacionales con estilos de vida, las crisis y la necesidad de afrontarlas en la estructuración de la actividad y, en relación dialéctica, el modo en que el territorio imprime su marca en los proyectos.

Palabras clave: Emprendedores. Subjetividad. Territorio.

"Nuestro norte es el sur" Joaquín Torres García

\section{INTRODUCCIÓN}

El artículo aborda la actividad emprendedora como ocupación desde una perspectiva cultural y pone en valor los diferentes modos en que se inscribe en la relación que el emprendedor establece con el territorio. Se busca así reflexionar sobre el papel del territorio en el modelaje de los proyectos ocupacionales de los entrevistados, su incidencia en el devenir del emprendimiento y el modo en que interactúa el territorio con las "temporalidades sociales" (Godard, 1996), en tanto tiempo y espacio constituyen factores clave en los procesos de socialización empresarial.

En este marco, se despliegan dos ideas fuerza concurrentes para desmarcar el análisis de la actividad del tratamiento económico clásico y adoptar una perspectiva inscripta en la tradición psicosociológica: la necesidad de problematizar la existencia de una cultura emprendedora y la noción de cultura en esa tendencia, y el imperativo de recuperar una perspectiva histórica y territorialmente situada de la actividad.

El corpus que se toma como referencia, remite a los hallazgos de un estudio sobre la actividad emprendedora en el que se buscó identificar, conocer y comprender cómo inciden los factores biográficos y territoriales en los procesos de creación de empresas. Desde el punto de vista metodológico, la investigación se inscribe en la tradición comprensiva, con el fin de reconstruir y analizar las trayectorias biográficas de emprendedores "no herederos" (Pailot, 2000). El 
trabajo de campo se realizó sobre una muestra intencional de empresarios de Argentina y Uruguay, en el marco de una orientación más amplia que busca captar las singularidades de los procesos de creación de empresas en América Latina.

Recuperando parte de la información obtenida a través de entrevistas biográficas, se muestran algunos hallazgos en relación a las articulaciones entre subjetividad y territorio, principalmente en relación a los modos en que se acoplan proyectos ocupacionales con estilos de vida, las crisis y la necesidad de afrontarlas en la estructuración de la actividad y también en relación dialéctica, el modo en que el territorio imprime su marca en los proyectos cuando no es pensable la idea de migrar.

\section{LA PROMOCIÓN DEL EMPRENDEDORISMO}

Abordar la actividad emprendedora como ocupación implica un análisis que se construye en ruptura con la esfera económica y que traspasa lo que se da en llamar "la promoción del emprendedorismo" o "la cultura emprendedora como prescripción”.

En el marco de las transformaciones del mundo del trabajo una nueva "cultura" prescribe a los trabajadores el comportamiento emprendedor. Estos cambios tienen alcance global y se expresan en las condiciones productivas en el que el trabajo se desenvuelve (Zarifian, 1996 \& Linhart, 1997) y en las exigencias de los nuevos escenarios laborales a los sujetos, que se derivan de la relevancia que adquiere el management en la reconfiguración de las sociedades postindustriales (Bauman, 2006; Dejours, 2006; Gaulejac, 2005; Sennett, 2006; Zarifian, 2001).

Las dinámicas organizacionales contemporáneas marcan el desarrollo de nuevas subjetividades que se expresan tanto en las relaciones con el trabajo y su organización como en las interacciones sociales que se dan en las situaciones de trabajo. Se propone o impone a los sujetos adquirir nuevas competencias: capacidad de adaptación a contextos de incertidumbre, de anticiparse a lo imprevisto, de adquirir iniciativa y discernimiento para tomar decisiones adecuadas y rápidas, de incorporar habilidades para planificar, organizar y controlar las tareas, de generar actitudes participativas y de colaboración en las relaciones con los otros y con la organización.

A su vez, las actuales relaciones de producción presentan una paradoja: el nuevo paradigma productivo hace que los trabajadores "no puedan participar efectivamente en la producción", y al mismo tiempo que "no puedan no participar en ella". En términos de Clot, la subjetividad es requerida y rechazada a la vez, 
se promueve su liberación, se la prescribe, se busca subordinarla y disciplinarla y a la vez se la considera un residuo de la modernización (Clot, 2008). Se pide al sujeto que opere como un intrapreneur, en un universo empresarial cada vez más codificado por tecnologías de gestión que fuerzan necesariamente el ajuste del sujeto a los criterios éticos y técnicos que esconden procedimientos, planillas, sistemas, protocolos.

Lo dicho permite captar las tensiones entre la persistencia de la centralidad del empleo en la sociedad y la emergencia de un discurso que propone un viraje hacia un estilo de vida emprendedor o un estilo de vida "wired" (Flores \& Gray, 2004). Se promueve así una idea de estilo de vida que remite a una "cosmovisión vinculada al sentido común y las prácticas sociales más extendidas" (Grimson \& Semán, 2002), cuestión problemática en tanto la utilización de esa categoría conduce a naturalizar un estado de cosas y a modelizar comportamientos. En este sentido, se impone la necesidad de un análisis cultural que trascienda las lógicas performativas de este discurso.

El fomento del estilo de vida emprendedor constituye una línea discursiva que muestra caminos alternativos a la idea de empleo de calidad, por tiempo indeterminado y protegido, que caracterizó las relaciones fordistas. Alienta a desarrollar las ideas emprendedoras y ser el "propio jefe". Incluye el estímulo de los "emprendimientos sociales" como estrategias de organización para algunos colectivos de desocupados.

Por fuera del asalariado, el fomento de la cultura emprendedora adopta otra forma que se integra también a lo que da en llamarse la "nueva cultura" del capitalismo: la actividad emprendedora propiamente dicha o los procesos de creación de empresas. El foco no está aquí en "ser emprendedor" como una cualidad actualmente deseable, sino el hecho concreto de la creación de empresas como actividad y "el espíritu empresarial" (entrepreneurship) de ciertos grupos sociales.

En nuestra región, este fenómeno se expresa en un aumento significativo de los emprendimientos y en el despliegue de un conjunto de políticas que promueven la implementación de programas de creación de nuevas firmas y de fomento del espíritu empresarial, impulsadas por el ámbito público y el sector privado (Kantis, 2004).

En este marco, una característica es el incremento de emprendedores "de primera generación", que provienen de familias con tradición de empleo, tendencia que puede explicarse a partir de factores articulados al cambio de paradigma en la organización del trabajo, el desarrollo de las Tics, el crecimiento del sector servicios y la crisis del empleo, que supone incremento del desempleo 
y procesos de precarización y deterioro del empleo existente (Boutillier \& Uzunidis, 2002).

Se promueve así la creación de empresas como parte de las políticas de desarrollo económico y se estimula la puesta en valor de la actividad empresarial en el marco de las políticas de empleo, la política educativa y las de desarrollo local o regional (Kantis, 2004). En nuestra región la literatura evidencia creciente interés en la actividad emprendedora como alternativa al empleo y como estrategia ocupacional frente a la desocupación; también como resultante de la profesionalización de la actividad cuentapropista y el autoempleo (Kantis, 2004; Valenzuela, Marquez, \& Venegas Leiva, 2001).

\section{EL HOMBRE-EMPRENDEDOR EN CLAVE SOCIO- ANTROPOLÓGICA}

Bajo las dos formas mencionadas, se propone un hombre-emprendedor capaz de sobrellevar(se) en un orden social inestable, fragmentario y precario. A propósito de ello, Sennett (2006) señala que muy pocos seres humanos son capaces de prosperar en estas condiciones y que en virtud de ello se esboza un "ideal" de hombre capaz de enfrentar tres desafíos:

a) manejar relaciones a corto plazo y manejarse a sí mismo, mientras se pasa de una tarea a otra, de un empleo a otro, de un lugar a otro;

b) reciclar sus propias habilidades cada ocho y doce años, en la medida en que el orden social emergente milita contra el trabajo artesanal y se celebra la habilidad potencial más que los logros del pasado; y

c) ser capaz de desprenderse del pasado, de descartar las experiencias vividas, como un consumidor siempre ávido de cosas nuevas.

El autor enfatiza la idea de que la mayor parte de la gente no es así, sino que necesita un relato de vida que sirva de sostén a su existencia, se enorgullece de las habilidades que ha adquirido para realizar algo específico y valora las experiencias por las que ha pasado; por lo cual este ideal cultural que se propone y requiere en las nuevas instituciones es perjudicial para muchos de los individuos que viven en ellas (Sennett, 2006).

Cuando Ortner (2005) retoma las contribuciones de Sennett señala que para este autor la crisis de la consciencia posmoderna es una crisis de orientación dentro de un mundo ininterpretable, o según el propio Sennett "ilegible". Refiere que un elemento fuerte de la propuesta de Sennett es la recuperación de la narración como herramienta, que evidencia la capacidad de las personas de 
relatar sus vidas de una manera coherente y significativa. No obstante, señala la importancia de analizar siempre las contracorrientes, las formaciones culturales alternativas, residuales, emergentes, porque la conciencia es cultural y también diversa o multifacética, en donde la complejidad y reflexividad constituyen el fundamento para cuestionar y criticar el mundo en el cual nos encontramos.

Cierto es que el fomento de la empresarialidad a tan masiva escala exige un análisis que integre la cuestión de la subjetividad y el poder en los procesos culturales. En esta línea, Ortner (2005) sostiene que el análisis cultural debe entrelazarse con el análisis de eventos y procesos sociales y políticos. En este sentido, cuando el análisis se vincula a las dimensiones históricas y sociopolíticas, es siempre un análisis en el cual los agentes se sitúan de maneras diferentes respecto del poder y tienen intenciones distintas (Ortner, 2005). Se busca así complejizar lo social e incorporar la subjetividad sin que ello implique una posición psicologista. La autora propone entender a la subjetividad como el conjunto de modos de percepción, investidos emocionalmente que movilizan a los sujetos; pero retomando a Williams (1977) incorpora también la idea de subjetividad aludiendo a las formaciones sociales y culturales que modelan, organizan y generan determinadas "estructuras de sentimiento". Así, esta investigación se sitúa en el espacio que articula el análisis de las formaciones culturales y los estados subjetivos de los sujetos, bajo una concepción del sujeto como un ser existencialmente complejo, que siente, piensa, reflexiona, construye y busca sentido (Ortner, 2005).

El concepto de cultura en uso en estas perspectivas performativas, evoca esa idea esencialista que se cuestiona actualmente en el campo antropológico (Grimson \& Semán, 2002; Dubar, 2002). Por una parte, de manera explícita o implícita remite a una espacialidad "territorial" o delimitación geográfica en tanto esa construcción del sujeto como emprendedor -que invisibiliza condiciones objetivas, trayectorias de vida, relaciones intergeneracionales y tantas otras cuestiones- remite casi exclusivamente a los trabajadores del conocimiento y en general a "la clase que vive del trabajo" (Antunes, 2003) en el marco de la actual división internacional del trabajo norte-sur.

Por otra parte, cuando se caracteriza al emprendedor como un sujeto adaptado al futuro por oposición a aquellos hombres -según Sennett la gran mayoría- que no pueden pensarse inscriptos en dicho canon, se da cuenta también de una operación que tiende a cristalizar o congelar diferencias y a establecer distinciones (Abu-Lughod, 1991) al interior mismo de esa "geografía" que pretende recortar. Al igual que la idea de "parias o advenedizos" de Hannah Arendt o de "establecidos u outsiders" (Elías, 2000), la oposición "emprendedores y burócratas" podría servir de expresión sintetizadora de la visión del trabajo que proponen algunos 
discursos del emprendedorismo y que sin duda impacta en las configuraciones identitarias (Elias, 1991; Dubar, 2002).

En contrapartida, desde una perspectiva crítica, la idea de una nueva cultura en el mundo del trabajo, o como propone Sennett $(2000 ; 2006 ; 2009)$ de manera consistente, "una nueva cultura del capitalismo", supone algo bien diferente: admitir la complejidad que adquiere el mundo del trabajo en la actualidad, su heterogeneidad y diversidad, y -fundamentalmente- que se trata de escenarios algunos evidentes y otros invisibilizados- cuya configuración es preciso reconstruir y cuyas significaciones e impactos en la subjetividad es preciso explorar.

Las contribuciones de Sennett resultan muy significativas para comprender el cambio cultural en el marco de los estudios del trabajo, y cuando Ortner (2005) recupera su propuesta resignifica la idea de una antropología de la subjetividad, concebida como estado mental, de actores reales inmersos en el mundo social y también como formación cultural que expresa, modela y constituye ese estado.

Así, una lectura crítica del mundo contemporáneo implica comprender no solo sus nuevas formaciones políticas, económicas y sociales, sino también una nueva cultura que puede leerse desde el punto de vista de los tipos de subjetividad que tiende a producir. En esta línea, Briones (2007) señala también la presencia de un giro discursivo que remite a la emergencia de nociones de sujeto descentrados, con identidades fragmentadas, fluidas, flexibles, disputadas.

El discurso del trabajador emprendedor exige comprender la diversidad de las prácticas de trabajo y examinar en qué condiciones se gestionan las diferencias, las desigualdades, la inclusión-exclusión y los dispositivos de explotación en procesos inter-culturales (García Canclini, 2004): la tendencia pro-emprendedora busca constituirse además en una alternativa al empleo para los grupos sociales empobrecidos, bajo la envoltura de políticas de acción social -estatales o no estatales-, canalizadas a través de programas y entendidas como emprendimientos sociales productivos o emprendimientos de subsistencia. Siguiendo a Coraggio (2008), se trata del "descubrimiento" de que hay un capital muerto que puede ser puesto en valor: los pobres, que son millones, tienen recursos que pueden convertirse en capital si son reconocidos y puestos en condición de ser movilizados, particularmente a través de su formalización jurídica y su mercantilización. Se trata entonces de probar que esos recursos y capacidades pueden incorporarse a las reglas del juego mercantil, luego de un proceso de formalización, incubación, protección, apoyo extra-mercantil o subsidio. Se trata de un mensaje que indica que para superar la exclusión estructural del sistema capitalista es necesario y posible construir un sector no capitalista de economía solidaria (Coragio, 2008), sin relaciones de explotación 
del trabajo, que se apoya en una base mercantil ("hay que pasar la prueba del mercado") pero que introduce valores de solidaridad, pluralidad social y cultural, respecto a la naturaleza, autonomía de gestión, democracia interna, etc.

Se resignifica también aquí el carácter emancipatorio del planteo de Ortner (2005), que adopta como supuesto que los hombres buscan siempre hacer sentido de sus vidas, fabricando diversas tramas de significados. La subjetividad, vista aquí como base de la agencia, permite comprender por qué las personas obran o tratan de obrar sobre el mundo aun cuando son objeto de ese obrar. La agencia no es una voluntad natural u originaria, adopta la forma de deseos e intenciones específicas en una matriz de subjetividad: de sentimientos, pensamientos y significados culturalmente constituidos.

En la tradición histórico cultural, Clot (2005) refuerza la idea de que para pensar la identidad es preciso saber que la acción humana no se produce en línea recta sino en círculos. Se construye a través del encuentro con una historia social que sitúa al sujeto permanentemente delante de nuevos problemas, que lo "provocan" y ponen a prueba su consistencia; se construye también a través de una historia individual en el curso de la cual -en respuesta a cada provocación de la historia social- el sujeto se provee de una pluralidad de vidas posibles, de un sistema de valores diversos a causa de sus dudas, deliberaciones internas y comparaciones que hace con respecto a otros. Por eso la subjetividad no es una simple escena interior sino una actividad singular de apropiación, incluso cuando el sujeto desconoce cómo opera. En relación a quienes buscan despojar al concepto de identidad de su dimensión subjetiva, el autor sostiene que una posición objetivista es tan frágil como cualquier psicologismo, en tanto el objetivismo pareciera asumir que es posible conocer el final de todas las historias, como si no pudiesen desarrollarse jamás de otro modo y conducir hacia otros destinos (Clot, 2008).

La capacidad del sujeto de reflexionar sobre la acción y sobre el decurso de su propia vida, constituye el pilar de las perspectivas histórico-culturales en torno a la identidad. Visión evolutiva y constructiva del despliegue de la subjetividad, en la que el sujeto reflexivo asigna sentidos a su acción y se constituye así en sujeto singular y social, estructurado por los sentidos asignados a la actividad. El lenguaje opera en la actividad, le otorga direccionalidad pero no la sustituye; como tampoco es pensable la actividad sin lenguaje, el puro hacer.

Para Clot (2005), historia social e historia personal se articulan como campo de posibilidades, y cada una posee sobre la otra la fuerza de la determinación a la vez que la contingencia que alberga múltiples posibilidades, y es en ese juego en donde el sujeto se expone. En esta perspectiva es posible pensar que sólo la 
elaboración con el sujeto de la información sobre su historia personal, permite implicarse en un trabajo que es a la vez indispensable, delicado y riesgoso: aquel de fijar de manera conjunta las etapas a través de las cuales se ha formado el ciclo de una existencia. El autor enfatiza en la actividad reflexiva que posibilita la construcción de la identidad personal/social, que en el caso de este estudio se analiza al reconstruir las significaciones que el emprendedor atribuye al territorio y a las dinámicas de pertenencia y apropiación.

\section{INSCRIPCIÓN SOCIO-HISTÓRICA Y TERRITORIAL DE LA EMPRESARIALIDAD}

Producir una ruptura con los estudios económicos clásicos sobre la actividad emprendedora exige también escapar a dos convenciones: la cuestión del borramiento de la perspectiva histórica y la subestimación del papel del territorio en los diversos análisis de la actividad.

Las primeras contribuciones sobre la actividad emprendedora se gestaron en el mismo nacimiento de la sociología europea en el siglo XIX que surgió del intento de comprender y explicar la gran transición de la sociedad tradicional a la sociedad moderna, con todos los procesos complejos que acompañaron la industrialización.

Sin embargo, la comprensión histórica no ocupó un lugar significativo en estos desarrollos, porque tanto las tradiciones microteóricas como las macroteóricas típicas de la sociología americana fueron abstraídas de la dimensión histórica de la realidad social, lo que puede calificarse como "presentismo ahistórico" (Sztompka, 1995). Así mismo, la localización de los estudios de empresarialidad en las escuelas de negocios enfatizó las perspectivas funcionalistas. El funcionalismo tuvo como centro a Estados Unidos, una sociedad cuya cuestión más apremiante era custodiar el orden social y que demandaba a sus sociólogos salvaguardar su delicado funcionamiento, lo que se buscó a través de la realización de diagnósticos empíricos concretos, principalmente en el nivel micrososciológico.

De allí la importancia de considerar la actividad empresarial como una práctica social, histórica y territorialmente situada, haciendo visible el anclaje del proyecto emprendedor en los distintos dominios de la vida, como un componente atravesado por marcas biográficas y contextuales. Así, la relación entre el sujeto y el proyecto no puede ser reducida a un mero encadenamiento de decisiones supuestamente racionales y exclusivamente orientadas a la maximización.

Esta inscripción evita el análisis de las características sustanciales del emprendedor como un actor heroico (Boutillier \& Uzunidis, 2002) y enfatiza 
los aspectos de la actividad que se deben a un tipo de inscripción relacional. Esto implica analizar la manera en que los actores se mueven en la heterogeneidad del mundo social y en la incompletud de su orden económico (Zalio, 2009). Se trata explorar las singularidades de la actividad, que se construyen a través de la captura que hace un actor social de ciertas oportunidades que otros no vieron o no supieron ver o, para decirlo de otra manera, de la capacidad de localizar heterogeneidades en la evaluación de los bienes económicos y permitirse recombinarlos o desplazarlos.

En este sentido, el estudio de los proyectos emprendedores ha evidenciado que las relaciones entre emprendedor y territorio no son lineales (Zalio, 2009). El emprendedor es con frecuencia un actor que sabe encontrar un buen equilibrio ente su inscripción en el entorno social y su necesaria desinscripción con vistas a mantener cierta autonomía. En este sentido, existe una paradoja en la inscripción del emprendedor en las redes territoriales en la medida en que expresan una dualidad: las personales y sociales, fundadas en el intercambio de información, el compromiso y la confianza; y otras de tipo impersonal y basadas en relaciones de mercado. El emprendedor debe entonces arbitrar entre estos diferentes tipos de relaciones (Zalio, 2009)

Entendemos que la perspectiva de Bozzano (2000) constituye un terreno fértil para reflexionar sobre la inscripción territorial de la actividad emprendedora, bajo la propuesta de tres grandes categorías: los territorios reales como espacios concretos, los territorios pensados, en el sentido de una territorialidad inteligente y los territorios posibles, como el espacio vivido y también como una categoría que alude a las intenciones y posibilidades personales y colectivas de imaginar un futuro y trabajar para ese futuro desde el presente.

\section{LO GLOBAL, LO LOCAL, EL TERRITORIO}

Hemos señalado que la problemática de la a-historicidad y la invisibilización de la cuestión del territorio constituyen dos problemas de abordaje de la empresarialidad que es preciso poner en discusión. Con esa intención hemos buscado escapar a la tendencia globalizadora de considerar la idea clásica del territorio como mercado para avanzar en una perspectiva que resignifique su dimensión psicosociológica.

Analizar el rol que juega el territorio en la nueva empresarialidad, supone considerar "lo local" como recurso del proyecto emprendedor y valorar su inscripción biográfica y su incidencia en la acción emprendedora. Esta perspectiva, complementando el abordaje socio-histórico pone en foco las tensiones entre lo global y lo local (Steiner \& Vatin, 2009) y cuestiona la tradición hegemónica de la 
sociología de la gran empresa y los estudios centrados en una visión "heroica" del empresario. Se propone una psicosociología de la actividad emprendedora que capture las particularidades con las que estos "nuevos" sujetos pueden apropiarse de lo global para preservar y potenciar la dinámica específica de un territorio (Zalio, 2009) en tanto ha sido resignificado subjetivamente como componente central del proyecto ocupacional.

En este sentido, Abu-Lughod (1991) remarca que en el actual escenario global existen muchas formas nuevas de vida, formas sincréticas, translocales, multiculturales y neotradicionales. La autora comparte con Appadurai (2001) que la homogeneidad y la heterogeneidad no son mutuamente excluyentes, y recuperando a Friedman (1990) sostiene: "La fragmentación étnica y cultural y la homogeneización modernista no son dos argumentos, dos visiones opuestas de lo que hoy acontece en el mundo, pero sí dos tendencias constitutivas de la realidad global. Integración y diferenciación son elementos que co-evolucionan". (p. 312).

Por su parte, Terence Turner sostiene que la cultura es un sistema de formas alternativas de acción social y por lo tanto debe ser entendida como un medio a través del cual un pueblo define y se produce a sí mismo como entidad social, en relación a su situación histórica en transformación (Turner, 1987). El autor señala también que la supervivencia cultural en el mundo moderno consiste en la tentativa de los pueblos de apropiarse de ese mundo en sus propios términos, planteo que resulta clave para la comprensión de las relaciones entre biografía y territorio.

En este sentido, se hace preciso avanzar en la comprensión de la inscripción social del emprendedor -en el espacio relacional, en las organizaciones, en las historias, en los mundos productivos y sociales-, y comprender cuál es el trabajo social necesario para "fabricar" un emprendedor. Este trabajo social puede observarse en el contexto de los emprendedores dirigentes de empresa, de ciertos trabajadores independientes y también en el contexto de los asalariados cuando son puestos en situación de desplegar comportamientos de gestión que hacen referencia explícita a la empresarialidad. (Zalio, 2009).

En esta línea, la gran mayoría de estos nuevos empresarios comparten una visión global -y digital- del mundo social y de los intercambios económicos. Esta visión no se contrapone con una concepción que otorga al territorio una importancia central en la generación de empresas, sino que expresa nuevas configuraciones y tensiones en el marco de un nuevo contexto regional. Esto puede expresarse en una visión instrumental del territorio, limitada a la idea de una localización productiva en base a las oportunidades de negocio existentes 
-mercado de factores, de regulaciones y políticas-, centradas en ciertas ventajas competitivas, en donde la equivalencia de las condiciones torna intercambiables los territorios.

\section{TERRITORIOS, SUBJETIVIDADES Y PROYECTO EMPRENDEDOR. PRINCIPALES HALLAZGOS}

El estudio permitió identificar diversas modalidades de subjetivación del territorio. Una de ellas, propone al territorio como un "polo" de un sistema global total. Esta visión del territorio se repite de modo significativo en los casos de emprendedores de servicios informáticos situados en las ciudades de Córdoba y Montevideo, ambas reconocidas como "polos tecnológicos".

Es el caso de Agustín, por ejemplo, un joven que constituyó una empresa de desarrollo de software con dos compañeros al finalizar sus estudios universitarios en computación y se instalaron en la incubadora de empresas del Laboratorio Tecnológico de Uruguay (LATU). Agustín considera que radicar su empresa en un polo tecnológico no solo le facilitó el crecimiento de su negocio y la posibilidad de consolidar la empresa rápidamente, sino que además le marca niveles de exigencia altos, que lo obligan a innovar:

\footnotetext{
Sobre mitad de año egresamos y estamos aquí en este suerte de Silicon Valley que le han llamado al LATU donde hay muchas empresas de tecnología, está ARTECH que es una de las mayores empresas de tecnología de aquí de Uruguay que es ese edificio que está ahí al frente, está una empresa que se dedica a hacer software bancario que le vende a bancos también; está la cámara uruguaya de tecnología aquí al lado y otras pequeñas empresas, esta IBM abajo. Tengo la suerte de conocer y saludar por el nombre y que me conozcan a mí, a los diez gerentes o dueños de las 10 empresas más importantes de Uruguay. Y bueno, para nosotros era clave poder estar aquí como empresa de software, y bueno, estamos trabajando actualmente desarrollando soluciones para varias empresas para aquí para el Uruguay pero también para el extranjero.
}

Estar en un territorio cuya característica es la densidad de empresas del mismo tipo, con una fuerte vinculación con el circuito científico y tecnológico y políticas públicas que estimulan el desarrollo de las pequeñas empresas, posibilita un interjuego entre lo global y lo local que permite un desarrollo protegido de la actividad. La empresa de Agustín y sus socios surgió de un concurso de proyectos que se planteó en una jornada de emprendedores universitarios y el proyecto fue apadrinado por una empresa de mediana envergadura que les dio la oportunidad de ser sus proveedores. Luego, en el proceso de incubación, fue posible contactarse con los empresarios más importantes del sector y hacer aprendizajes clave para 
el desarrollo, principalmente en lo relativo a las estrategias comerciales para la exportación, que para el caso de Uruguay, que tiene un mercado interno muy pequeño, resulta imprescindible.

Como vemos en este ejemplo, el territorio puede constituirse en un tejido denso en capacidades y ser vivido por el emprendedor como un reservorio de experiencias comunes y de cooperación institucional, constituyéndose en un laboratorio para innovar y proyectarse al futuro. En este marco, otra fórmula posible sería la que nos propone uno de los entrevistados: "Precisamente porque el mundo es global, es posible emprender en este lado del mundo y es este el lugar en donde vale la pena hacerlo". En esta línea, es posible considerar que al menos una parte de los nuevos empresarios se hallan más implicados y comprometidos que otros con el desarrollo de la región en la se inscriben sus proyectos, al punto en que el territorio mismo es parte del proyecto.

En la empresa que tomamos como ejemplo, la apertura al mundo desde Uruguay parece ser la vía óptima de desarrollo del proyecto. Cuando indagamos en el interés de Agustín y sus socios de emprender en otro país pudo constatarse que la comprensión del mercado como una instancia global y la valoración positiva de las oportunidades que ofrecen otros mercados no implica necesariamente la renuncia al arraigo:

Si la empresa requiriera abrir sucursal en México o Brasil y para mí fuera una coportunidad y alguien se la tiene que jugar yo me la jugaría. Pero no es el objetivo. Yo no me veo el resto de mi vida en el extranjero, no lo veo, o sea entiendo que el modelo de negocios que estamos planteando nosotros va a requerir un gran esfuerzo nuestro en viajes y en trabajo...pero no cabe renunciar a todo. yo tenía un profesor que decía "si ustedes quieren tener su empresita y comer asado todos los domingos en Atlántida fantástico, pero eso no es internacionalizarse" van a tener que esforzarse van a tener que viajar, y eso va a implicar muchas horas, y bueno a eso si estamos dispuestos, pero siempre que se pueda mantener el arraigo.

No perder arraigo, implica de algún modo poner un techo al crecimiento:

Me lo han contado diferentes emprendedores que dicen la empresa mía creció hasta acá porque yo quise que crezca hasta acá, porque yo la hago crecer hasta acá viajando 20 veces al año, 20 es lo máximo que yo pienso viajar, no quiero viajar 40 , capaz que si viajara 40 veces duplicaría la facturación y duplicaría la dimensión, pero yo con la dimensión que tengo vivo cómodo.

Pero el límite en términos de crecimiento puede balancearse a través de un proceso de intensificación de la actividad emprendedora. En el caso de Agustín, 
la posibilidad de conocer personas que se dedican a crear y vender empresas fue clave para imaginar que su proyecto ocupacional puede desenvolverse en un mismo territorio a través de una dinámica de innovación muy intensa:

En Boston, fue una experiencia extraordinaria para mí, y vi como emprendedores o profesores, que estaban dándonos clases, prácticamente son emprendedores seriales, son tipos que fundaron una empresa les dieron millones de dólares y están ya se aburrieron pensaron otra idea la generaron, tuvieron la capacidad de llevarla adelante, la vendieron a una multinacional enorme, y después fueron y generaron otra empresa yo acá en Uruguay conozco varios ejemplos de ésos.

El caso de Agustín muestra que la empresarialidad que se despliega actualmente en América Latina, se hace evidente en las múltiples articulaciones entre biografía y territorio. No se trata solamente de advertir el potencial de un territorio, sino de explorar cómo o de qué manera unas particulares trayectorias de vida se articulan en un espacio determinado.

\section{LAS CRISIS: LA TENSIÓN ENTRE MIGRAR O RESISTIR}

La cuestión de las crisis económicas constituye un componente característico de las trayectorias de emprendedores en nuestra región. En el caso de este estudio, su presencia se intensifica en dos sentidos. Por una parte, porque indagamos en países con economías emergentes, pero también porque optamos reconstruir trayectorias de emprendedores de primera generación, que en muchos casos han iniciado sus proyectos a partir de la pérdida de un empleo asalariado.

Julieta, Pablo y Sebastián son socios en una empresa dedicada a la traducción de textos para empresas. Trabajaban los tres en una empresa de idénticas características, de origen americano, que estaba radicada en la ciudad de Rosario, Argentina. En el año 2000, debido a la grave crisis económica que atravesaba nuestro país, la empresa decide cerrar sus puertas y les ofrece trasladarlos a otras sedes de la empresa en el exterior. Si bien las condiciones de trabajo que les ofrecían eran muy buenas, decidieron quedarse y fundar su propia empresa de traducción de textos, a la que llamaron "Ushuaia”.

Aparece aquí otro dilema recurrente en las trayectorias: quedarse o partir. La crisis económica y la pérdida del empleo pueden implicar el despliegue de modalidades de afrontamiento que incluyen tanto la posibilidad de emigrar, como la libertad para (re) trazar la propia trayectoria ocupacional en función de un proyecto deseado que se sostiene en el arraigo al territorio. 
La crisis en este caso se constituyó en un imperativo que obligó a actuar inmediatamente e incluso a invitar a otros a sumarse:

La empresa no surgió como una decisión estratégica... yo hoy viéndolo después de 10 años creo que la empresa surgió como una balsa, o sea trabajábamos en un barco que se estaba hundiendo [...], fue como una balsa, fue decir "bueno a ver, los que no se van a ir a otros lugares, los que no van a ser movidos por la empresa y que no se quieren mudar de acuerdo a la propuesta que les haga la empresa...bueno, nosotros vamos a hacer una empresa nueva acá, así que el que se quiera sumar, que se sume. Pero era una cuestión digamos solidaria, porque realmente en ese momento no había otras empresas de traducción, no había ninguna en ningún lado.

Cuando preguntamos a este grupo de emprendedores porqué Ushuaia, es posible advertir que el territorio es el primer trazo de una identidad compartida. La página web de la empresa dice:

La ciudad de Ushuaia, situada en la provincia argentina de Tierra del Fuego, es la

ciudad más austral del mundo. En la lengua aborigen Yamana, su nombre significa: "bahía que apunta hacia el fin". Este nombre representa no sólo la distancia figurativa que podemos recorrer para asegurar la satisfacción del cliente, sino también nuestro profundo conocimiento de los matices y complejidades de las lenguas y culturas que coexisten en América Latina. Tanto en América Latina como a lo ancho del mundo el nombre Ushuaia Solutions ha llegado a significar confiabilidad, flexibilidad, creatividad y absoluto compromiso de excelencia y de satisfacción del cliente. Lo invitamos a descubrir por qué"1

En la voz de los emprendedores, es posible advertir la construcción de múltiples sentidos, que articulan lo biográfico a lo territorial y a la actividad misma:

Bueno, Ushuaia por dos motivos básicos: uno, que era que nosotros queríamos que la empresa tuviera un nombre argentino, muy bien identificado con Argentina , y que estuviera asociado con cosas buenas. Como fue el año 2000, Ushuaia participó de la celebración del milenio, entonces había, estuvo repitiéndose el nombre en la prensa extranjera porque bailó Julio Boca... era fácil de pronunciar para un extranjero, por la "shua" y todo esto, y además era un homenaje casi privado digamos mío y de Sebas a Patrice (un ex cliente), que nos había dado el primer proyecto en el que habíamos cometido un error y se llamaba "Proyecto Ushuaia”, entonces era como decir bueno le ponemos el nombre, un nombre que está copado que está bueno y que además tiene significado privado. (Julieta)

\section{Sebastián agrega:}

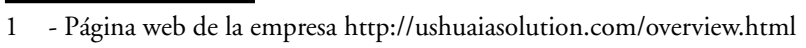


Eso sí fue estratégico, decir que queríamos que fuera argentino y que fuera bien identificado con Argentina y que no nos interesaba que fuera identificado con otro porque nosotros éramos argentinos, porque ahora esto está todo deslocalizado digamos no? Está bueno recuperar ese valor de estar acá, de trabajar acá, de vivir acá. Desde que nosotros empezamos la empresa hasta ahora el hecho de haber estado acá nos permitió a todos seguir haciendo vida, cada uno desarrolló su familia, desarrolló sus cosas que yo no sé si en otro lugar del mundo lo hubiéramos podido hacer porque ya veníamos con historia yo ya estaba casada tenía chicos, Pablo estaba de novio, Seba también estaba de novio o sea... (Julieta).

\section{Pablo agrega:}

Yo estaba en pareja pero todavía no convivíamos incluso yo di el salto de ir a convivir a partir de, a partir de la fundación de la empresa prácticamente habíamos encontrado el lugar y la oficina que habíamos ido a buscar con Juli que vimos el lugar y dijimos "acá está perfecto porque llega el cable y que se yo...pero además...yo toco en una banda de rock y eso era algo que no podía abandonar por nada del mundo.

Aquí es la historia de un nombre, "Ushuaia" la que nos cuenta la historia del quedarse o partir y las razones biográficas que invitaron al arraigo: razones que enlazan los distintos dominios de la vida, las cosas que pueden construirse aquí y las que no pueden dejarse "por nada del mundo". Pero también se trata de situar la actividad en un territorio y convocar desde allí, asumir el desafío de un proyecto que obligue al mundo a mirar hacia aquí.

\section{EMPRENDER SURFEANDO LAS CRISIS}

Olga tiene 55 años y junto a su hijo Joaquín gestiona un Hostel en La Paloma, Uruguay. No es la primera vez que desarrolla un emprendimiento y define su trayectoria como "estar siempre reconvirtiéndose, de acuerdo a cómo va cambiando la región". Olga explica sus iniciativas emprendedoras en función de su necesidad de vivir en La Paloma y de desplegar un estilo de vida "aventurero". Un estilo que se caracteriza por tomar riesgos y que en cierto modo emula el estilo de vida de sus padres, que llegaron al pueblo en los años 40 .

\section{Dice Olga:}

[...] una de las contras más importantes del Uruguay para emprender es la importancia que tiene el empleo público y las mejoras en los salarios que ha recibido de los últimos gobiernos. Se hace un llamado para veinte vacantes en cualquier empresa del estado y se presentan veinte mil personas. Y claro, si entraste, te colocaste y...y. Solucionaste tu futuro...pero quien se viene para aquí, precisamente no quiere esa vida y no aspira a un empleo público, entonces tiene que estar dispuesto a experimentar, a probar, a ver cómo aplica lo que sabe o le da una vuelta y con lo que sabe inventa algo nuevo. 
La crisis -o las crisis- también están aquí presentes, pero ya no se trata de migrar ni de resistir arraigando un proyecto, sino más bien de "surfear" la crisis, de acompañar con los propios movimientos su desarrollo, de acoplarse a sus transformaciones. De ir acomodándose a los cambios que va teniendo la región y que van obligando a reconvertir las propias actividades.

Olga puede describir este movimiento como algo natural y a la vez extraordinario: Mi padre se vino a vivir acá y a hacer cosas en el '43, que no había nada. Vino con ese grupo de amigos, era como espíritu de pioneros y hacían aceite de tiburón que no había sintético todavía y entonces había mucha demanda. Salaban el tiburón para hacer bacalao y bueno, le interesaba el mar y coleccionaba caracoles y sabía mucho de algas. Para estudiar las algas se pegan sobre papel, se secan y bueno ahí se clasifican y quedan tan lindas que entonces bueno un día me sugirió "mirá que bueno que queda esto" entonces yo empecé a juntar algas y a hacer tarjetitas y eran una cosa muy novedosa, todo el mundo las veía en la playa entonces me iba bárbaro en la feria.

En el caso de Olga, el desarrollo de la actividad implicó pasar de ser feriante en la playa a establecerse en un local, pero nunca necesariamente haciendo lo mismo. Acompañar las transformaciones de La Paloma supone ir siguiendo las modas de cada temporada, pero también los imperativos de las crisis económicas. Siguiendo las tendencias, Olga hizo ropa teñida artesanalmente, un local de comidas en la playa, otro de artesanías con el que tuvo mucho éxito durante trece años.

Sin embargo, seguir las modas o -mejor aún- generarlas, no es una receta infalible. Olga narra también algunos fracasos y en su relato puede advertirse que saber o al menos intuir lo que puede "funcionar" en territorio no siempre es suficiente:

También está el fracaso de las hamacas...Fue como una cosa de bastante desinformación en general, de no estar al tanto. Un poco la vida de La Paloma que también tiene como un aparte de lo que pasa en el mundo. Quise incorporar un producto que me parecía que era muy adecuado para la zona, que no existía y que yo conocía, que son un tipo de hamaca de Nicaragua, teníamos una divina y bueno se me metió en la cabeza que quería traer hamacas de Nicaragua para vender acá y que como era la época del dólar a la par a los argentinos les decías "u $\$$ s 100 cuesta" y todo a cien dólares no era nada y estaba internet recién comenzando para mí, entonces bueno entré a internet y cuando me quise acordar hice una importación de hamacas. Sin medir, sin averiguar por ejemplo cuál era el impuesto del estado uruguayo sobre el algodón, que es una industria protegida, entonces me costó lo mismo el impuesto que pagué que el producto incluyendo el flete aéreo. 
Y ahí fue la devaluación en Brasil, que hizo el efecto samba sobre Buenos Aires. El 20 de enero no había nadie en La Paloma, yo salía a la calle y me decía "que pasa? porque no hay nadie?" y me decían: "se fue todo el mundo a Bs As porque hay corrida bancaria, no te enteraste?”. Bueno, me quedé con el clavo de las hamacas, al año siguiente seguía más o menos esa crisis, se fue el 2000, después vino la crisis del 2002, con lo que demoré 5 años en terminar de vender las hamacas por abajo del costo y nunca pude pagar el préstamo que había pedido para comprarlas.

Y bueno y a partir de ahí empecé a repuntar porque al vender eso aunque no me lo pagaron al contado empecé a acomodarme de otra manera, a llenar agujeros, y compré unos terrenos muy baratos que yo me di cuenta que en poco tiempo iban a valer mucho acompañando a un amigo los vi por allá perdidos, y dije "éstos, mirá, no valen nada, son pozos, cuánto cuestan?” "u\$s1000” bueno, los compré, a los 3 años los vendí en u\$s12.000 entonces ahí bueno empecé a, pagué la deuda porque además asumió el Frente Amplio y a los pequeños deudores menores de u\$s15.000 les hicieron una quita del 50\% pagando de contado, entonces pagué al contado la deuda con esa quita y me empecé a estabilizar de nuevo, salí a flote otra vez.

Para Olga, el hundirse cada tanto y volver a salir a flote es parte de surfear las crisis en La Paloma, a la vez que se trata de comportamientos inherentes a la naturaleza de la actividad emprendedora, bajo la forma de "tomar riesgos". En los emprendimientos life style la toma de riesgos no siempre es calculada y responde más a la necesidad de actuar, de intervenir cuando lo que entra en riesgo es la posibilidad misma de sobrevivir en el territorio que se ha elegido para vivir:

Lo mío es mas de sobreviviente que, o sea yo no tengo la mentalidad ni la disposición empresarial porque tampoco quiero crecer, tener empleados y que se yo, esa cosa de [...] no, no, no, siempre emprender en una cosa que uno pueda manejar a escala humana, no me interesa el crecimiento, no me interesa ser una empresaria, soy una sobreviviente y simplemente quiero estar aquí (risas).

\section{APERTURAS: EL TERRITORIO INTERNALIZADO}

La investigación permitió comprender que en el territorio se expresan las tensiones entre necesidades y oportunidades y que puede operar como un contexto de producción/construcción de sentido, como el escenario de anclaje de un proyecto. Se trata en cierto modo de reconocer al territorio como un espacio semiótico, campo en el que se inscribe lo anhelado, geografía en la que acontece lo que importa.

Con estas contribuciones, en clave de apertura, se buscó resituar la cuestión de la empresarialidad como práctica social e históricamente situada y destacar 
cómo los abordajes psicosociológicos contribuyen a enriquecer los estudios sobre empresarialidad, particularmente en el caso de América Latina. En función de ello, hemos propuesto sustituir el enfoque demográfico y las estrategias metodológicas tradicionalmente utilizadas para los estudios en empresarialidad -cuestionarios y entrevistas-, por el enfoque biográfico y el uso de la entrevista biográfica y el análisis de trayectorias, como recursos técnicos privilegiados.

En el estudio se focalizó en el papel que juega el territorio en la historia de los emprendedores, las experiencias vividas, los valores compartidos, las disposiciones construidas en la dinámica de las redes intergeneracionales, los lazos que se construyen en los cursos de vida. Importa también el territorio en términos del lugar que ocupa en el porvenir. No necesariamente desde una posición en la que el emprendedor busca preservarlo, sino también cuando busca hacerlo propio o cuando lo transita guiado por una impronta transformadora, o alguna de las múltiples formas en que la subjetividad logra situarse.

El interrogante central admite doble cara: ¿cómo un territorio puede "fabricar" un emprendedor? La pregunta implica reflexionar acerca de cómo opera la subjetividad en el curso de vida de estos emprendedores para situarse en un territorio y qué sentidos le asigna a éste en su trayectoria y proyecto, es decir, cómo un emprendedor construye un territorio.

Las aproximaciones de la economía, la sociología y la geografía económicas, particularmente en sus vertientes institucionalistas, constituyen un marco de referencia significativo para la búsqueda que proponemos y nos ofrecen un punto de partida auspicioso. No obstante, desde la psicosociología, nuestra mirada posiciona al actor social como lugar de intersección del conjunto de contradicciones a las cuales es confrontado en su existencia: porque está sometido a influencias múltiples y a exigencias conflictuales, busca elaborar respuestas, estrategias y proyectos. 


\section{REFERÊNCIAS}

Abu-Lughod, L. (1991). Writing against culture. En R. Fox (Ed.), Recapturing anthropology: working in the present. Santa Fé: School of American Research Press.

Antunes, R. (2003). ¿Adios al trabajo? ensayo sobre las metamorfosis y el rol central del mundo del trabajo. Buenos Aires: Herramienta.

Appadurai, A. (2001). La modernidad desbordada: dimensiones culturales de la globalización. México: Ediciones Trilce-FCE.

Bauman, Z. (2006). Ética pós-moderna. (3a ed.) São Paulo: Paulus.

Boutillier, S., \& Uzunidis, D. (2002). Comment ont-ils réussi ?: l'histoire des entrepreneurs, du XVII siècle à nos jours. Levallois-Perret: Studyrama.

Bozzano. H. (2000). Territorios reales, territorios pensados, territorios posibles: aportes para una teoría territorial del ambiente. Buenos Aires: Espacio Editorial.

Briones, C. (2007). Teorías performativas de la identidad y performatividad de las teorías. Tábula Rasa, Bogotá, Colombia(6), 55-83.

Clot, Y. (2008). Travail et povoir d'agir. Paris: PUF.

Clot, Y. (2005, 30 dezembro). L'autre illusion biographique. Récupéré de: http:// enquete.revues.org/document $99 . \mathrm{html}$

Coraggio, J. L. (2008). La sostenibilidad de los emprendimientos de la economía social y solidaria. Otra economía: revista Latinoamericana de Economia Social y Solidaria, 2(3), 41-57.

Dejours, C. (2006). La banalizacioin de la injusticia social. Buenos Aires: Topia.

Descripcion general (2017). Ushuaia. Rosario. Recuperado a partir de http:// ushuaiasolutions.com/ESP/overview.htm

Dubar, C. (2002). La crisis de las identidades: la interpretación de una mutación. Barcelona, España: Bellaterra.

Elias, N. (1991). La sociedad de los individuos: ensayos. Barcelona: Península.

Elías, N. (2000). Introducao: ensaio teorico sobre as relacoes establecidosoutsiders. En N. Elías, \& J. Scotson, Os establecidos e os Outsiders: sociología 
das relacoes de poder a partir de uma pequena comunidade. Río de Janiero: Jorge Zahar.

Flores, F., \& Gray, J. (2004, 12 julho). El espiritu emprendedor y la vida wired: el trabajo en el ocaso de las carreras. Recuperado a partir de http://www. atinachile.cl/content/view/8411/Papers-Documentos-en-PDF.html: http:// www.atinachile.cl/node/83

Fiedmand, J. (1990). Being in the World: globalization and Localization. Theory, Culture \& Society, London, 7, 311-328.

García Canclini, N. (2004). Diferentes, desiguales y desconectados. Barcelona: Gedisa.

Gaulejac, V. (2005). La société malade de la gestion: idéologie gestionnaire, pouvoir managérial y harcèlement social. Paris: Editions du Seuil.

Godard, F. (1996). El debate y la práctica sobre el uso de las historias de vida en las Ciencias Sociales. En F. Godard \& R. Cabanes (Ed.) Uso de las historias de vida en las Ciencias Sociales. (pp. 5-55). Bogota: CIDS.

Grimson, A., \& Semán, P. (2002). Presentación de la cuestión de la cultura. Etnografías Contemporáneas: Revista del Centro de Estudios en Antropología, 1(1), 1-12.

Kantis, H. (2004). Desarrollo emprendedor: América Latina y la experiencia internacional. . Nueva York: Banco Interamericano de Desarrollo.

Linhart, D. (1997). La modernización de las empresas. Buenos Aires: Asociación Trabajo y Sociedad.

Ortner, S. (2005). Geertz, subjetividad y conciencia posmoderna. Etnografías Contemporáneas, 1(1), 25-54.

Pailot, P. (2000). La mémoire en héritage: éléments d'analyse socio-psychique de la socialisation entrepreneuriale anticipée. In Anales, 5 Congrès International Francophone sur la PME. (pp. 1-22). Lille: AIREPME.

Sennett, R. (2000). La corrosión del carácter. Barcelona: Anagrama.

Sennett, R. (2006). La cultura del nuevo capitalismo. Barcelona: Anagrama.

Sennett, R. (2009). El artesano. Barceloa: Anagrama. 
Steiner, P. \& Vatin, F. (2009). Traité de sociologie économique. Paris: PUF.

Sztompka, P. (1995). La nueva sociología histórica: concreción y contingencia. En P. Sztompka. Sociología del cambio social. Alianza: Madrid.

Turner, T. (1987). Representing, resisting, rethinking. Historical. México: Gedisa.

Valenzuela, M. E., Marquez, F., \& Venegas Leiva, S. (2001). Construyendo microempresa en Chile: trayectorias laborales de hombres y mujeres . Revista Latinoamericana de Estudios del Trabajo, 7(13),139-159.

Williams, R. (1977). Marxism and Literature. Oxford: Oxford University Press.

Zalio, P.P. (2009). Sociologie économique des entrepreneurs. En P. Steiner, \& F. Vatin (Ed.), Traité de sociologie économique (pp. 573-607). París: PUF.

Zarifian, P. (1996). Travail et communication. Paris: PUF.

Zarifian, P. (2001). Temps et modernité. Le temp comme enjeu du monde moderne. . Paris: L'Harmattan. 